\title{
Electronic properties of oxidized cyclometalated diiridium complexes: spin delocalization controlled by the mutual position of the iridium centres
}

Article

Accepted Version

Hartl, F., Hu, Y. X., Zhang, J., Zhang, F., Wang, X., Jun, Y. and Liu, S. H. (2020) Electronic properties of oxidized cyclometalated diiridium complexes: spin delocalization controlled by the mutual position of the iridium centres. Chemistry- A European Journal, 26 (20). pp. 4567-4575. ISSN 1521-3765 doi: https://doi.org/10.1002/chem.201904894 Available at https://centaur.reading.ac.uk/88150/

It is advisable to refer to the publisher's version if you intend to cite from the work. See Guidance on citing.

To link to this article DOI: http://dx.doi.org/10.1002/chem.201904894

Publisher: Wiley

All outputs in CentAUR are protected by Intellectual Property Rights law, including copyright law. Copyright and IPR is retained by the creators or other copyright holders. Terms and conditions for use of this material are defined in the End User Agreement. 


\section{www.reading.ac.uk/centaur}

\section{CentAUR}

Central Archive at the University of Reading

Reading's research outputs online 


\section{CHEMISTRY A European Journal}

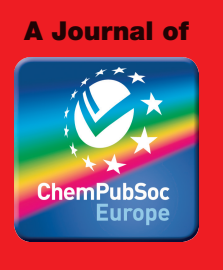

\section{Accepted Article}

Title: Electronic properties of oxidized cyclometalated diiridium complexes: Spin delocalization controlled by the mutual position of the iridium centres

Authors: Frantisek Hartl, Yuxuan Hu, Jing Zhang, Fangfang Zhang, Xiaoyan Wang, Jun Yin, and Shenghua Liu

This manuscript has been accepted after peer review and appears as an Accepted Article online prior to editing, proofing, and formal publication of the final Version of Record (VoR). This work is currently citable by using the Digital Object Identifier (DOI) given below. The VoR will be published online in Early View as soon as possible and may be different to this Accepted Article as a result of editing. Readers should obtain the VoR from the journal website shown below when it is published to ensure accuracy of information. The authors are responsible for the content of this Accepted Article.

To be cited as: Chem. Eur. J. 10.1002/chem.201904894

Link to VoR: http://dx.doi.org/10.1002/chem.201904894 


\title{
Electronic properties of oxidized cyclometalated diiridium complexes: Spin delocalization controlled by the mutual position of the iridium centres
}

\author{
Yu Xuan Hu, ${ }^{[[a]}$ Jing Zhang, ${ }^{\|[a]}$ Fangfang Zhang, ${ }^{[a]}$ Xiaoyan Wang, ${ }^{[a]}$ Jun Yin, ${ }^{[a]}$ František Hartl|[b] and \\ Sheng Hua Liu*[a]
}

\begin{abstract}
Four cyclometalated diiridium complexes, with $\mathrm{IrCp}^{*} \mathrm{Cl}$ $\left(\mathrm{Cp}^{*}=\eta^{5}-\mathrm{C}_{5} \mathrm{Me}_{5}{ }^{-}\right)$termini bridged by $1,4-$ and $1,3-$ bis $(p$-tolyliminoethyl)benzene $(\mathbf{1}, \mathbf{2})$, or 1,4- and 1,3-bis(2-pyridyl)benzene $(\mathbf{3}, \mathbf{4})$, were prepared and characterized by nuclear magnetic resonance (NMR) spectroscopy and single-crystal X-ray diffraction (complexes 1, 2 and 4). The two iridium centres in complexes $\mathbf{1}$ and $\mathbf{3}$ are thus bound at the central benzene ring in the para-position (trans-Ir2), while those in complexes 2 and $\mathbf{4}$ in the meta-position (cis-lr2). Cyclic voltammograms of all four complexes show two consecutive one-electron oxidations. The potential difference between the two anodic steps in $\mathbf{1}$ and $\mathbf{3}$ is distinctly larger compared to $\mathbf{2}$ and $\mathbf{4}$. The visible - near-infrared (NIR) - short-wave infrared (SWIR) absorption spectra of trans-Ir2 monocations ${1^{+}}^{+}$and $3^{+}$are markedly different from those of cis-Ir2 monocations $2^{+}$and $4^{+}$. Notably, strong nearinfrared electronic absorption appears only in the spectra of $1^{+}$and $3^{+}$while $2^{+}$and $4^{+}$absorb only weakly in the NIR-SWIR region. Combined DFT and TD-DFT calculations have revealed that (a) $\mathbf{1}^{+}$ and $\mathbf{3}^{+}$(the diiridium-benzene trans-isomers) display HOSO and LUSO evenly delocalized over both molecule halves, and (b) their electronic absorptions in the NIR-SWIR region are attributed to mixed metal-to-ligand and ligand-to-ligand charge transfers (MLCT and LLCT). In contrast, cis-isomers $\mathbf{2}^{+}$and $\mathbf{4}^{+}$do not feature this stabilizing $\pi$-delocalization but a localized mixed-valence state showing a weak IVCT absorption in the SWIR region.
\end{abstract}

\section{Introduction}

Over the past few decades, the advent of silicon-based electronic devices brought about a significant development in the field of electronic technology. The size limitation of siliconbased solid-state electronic devices has presented one of the biggest challenges for their miniaturization and the capacity multiplication of electronic chips. In recent years, the field of

[a] Y. X. Hu, "Dr. J. Zhang," F. Zhang, X. Wang, Prof. Dr. J. Yin, and Prof. Dr. S. H. Liu*

Key Laboratory of Pesticide and Chemical Biology, Ministry of Education

College of Chemistry, Central China Normal University

Wuhan 430079, P.R. ChinaDepartment

E-mail: chshliu@mail.ccnu.edu.cn

[b] Prof. Dr.F. Hart"

Department of Chemistry

University of Reading

Whiteknights, Reading RG6 6AD, United Kingdom

E-mail: f.hartl@reading.ac.uk

"These authors contributed equally to this work.

Supporting information for this article is given via a link at the end of the document.

molecule electronics has attracted attention of scientists due to the great potential for further drop in device dimensions. Multiple redox-active compounds have widely been explored for applications in molecular electronics technology $y^{1-5}$ and information storage $\mathrm{e}^{6-8}$, and as molecular wires in a mixed-

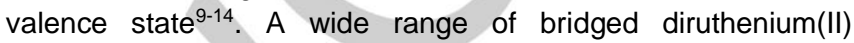
complexes belonging to the latter family have been thoroughly explored due to their facile accessibility and high stability. The ruthenium centres in a major part of the these $R u(B L) R u$ complexes are linked to the conjugated bridging ligands (BL) via ethynyl or vinyl groups. ${ }^{15-21}$ The related cyclometalated ruthenium(II) complexes are less frequently reported, despite of embedding the metal centre into the $\pi$-conjugated system, which is conducive to increased conjugation between the metal centres and the carbometalated ligands ${ }^{22-30}$. The synthesis of cyclometalated diruthenium complexes involves some challenges, such as high reaction temperature and tedious purification. Isoelectronic iridium(III) benefits from high hydrocarbon activation ability facilitating the formation of carbon-iridium bonds ${ }^{31-33}$ and the preparation of cyclometalated oligonuclear iridium complexes in high yields under mild conditions. ${ }^{34-35}$ In this work, we have synthesized four cyclometalated diiridium complexes (Chart 1 ) featuring 1,3- and 1,4-bis ( $p$-tolyliminoethyl)benzene $(\mathbf{1}, \mathbf{2})$ and 1,3- and 1,4-bis(2pyridyl)benzene $(3,4)$ bridges, and fully characterized them by NMR spectroscopy, elemental analyses and single-crystal X-ray diffraction (1, 2 and 4). The two iridium centres occupy parapositions at the core benzene ring in complexes $\mathbf{1}$ and $\mathbf{3}$, and meta-positions in complexes 2 and 4 (Chart 1). The redox and electronic absorption properties of 1-4 and their stable monocations were investigated by cyclic voltammetry combined with UV-Vis-NIR and SWIR-IR spectroelectrochemistry and complemented by density functional theory calculations.
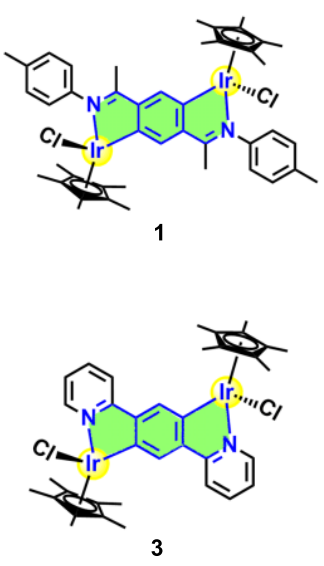

Chart 1. Schematic molecular structures of studied diiridium complexes 1-4.
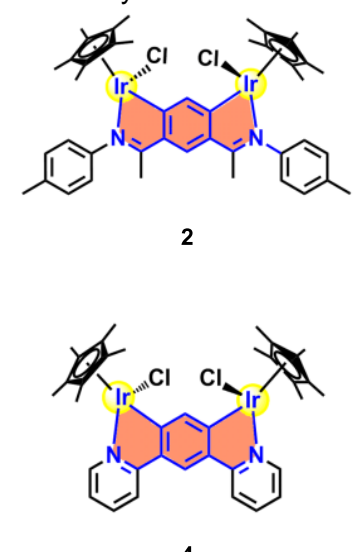

4 


\section{Results and Discussion}

\section{Syntheses and Characterization}

The precursor complex $\left[\mathrm{Cp}^{*} \mid \mathrm{ICl}_{2}\right]_{2}$ was prepared from $\mathrm{IrCl}_{3} \cdot \mathrm{xH}_{2} \mathrm{O}$ according to a literature procedure. ${ }^{36}$ The general synthetic route for the preparation of cyclometalated diiridium complexes 1-4 is outlined in Scheme 1. All complexes were synthesized in high (>70 \%) yields. 1,4-bis ( $p$-tolyliminoethyl)benzene (a) was obtained by the condensation reaction of $p$-toluidine and 1,4diacetylbenzene in the presence of an excess of sodium bicarbonate, while 1,3-bis( $p$-tolyliminoethyl)benzene (b) was synthesized by a literature method. ${ }^{37}$ Ligand precursors $1,4-$ and 1,3-bis(2-pyridyl)benzene (c and $\mathbf{d}$ ) were obtained in moderateto-high yields by palladium(II)/copper(0)-catalyzed crosscoupling reactions of 2-bromopyridine with 1,4- and 1,3benzenediboronic acid, respectively. All these compounds were characterized by ${ }^{1} \mathrm{H}$ and ${ }^{13} \mathrm{C}$ NMR spectra (Supporting Information). In ${ }^{1} \mathrm{H}$ NMR spectra, the methyl groups at the $\mathrm{Cp}^{*}$ ligands resonate as sharp and strong singlets at 1.4-1.7 ppm. In the ${ }^{13} \mathrm{C}$ NMR spectra of complexes $\mathbf{1 - 4}$, the $\mathrm{Cp}^{*}$ signals are observed near $90 \mathrm{ppm}$ and $9 \mathrm{ppm}$. The crystal structures of 1, 2 and $\mathbf{4}$ have been elucidated by $\mathrm{X}$-ray diffraction.

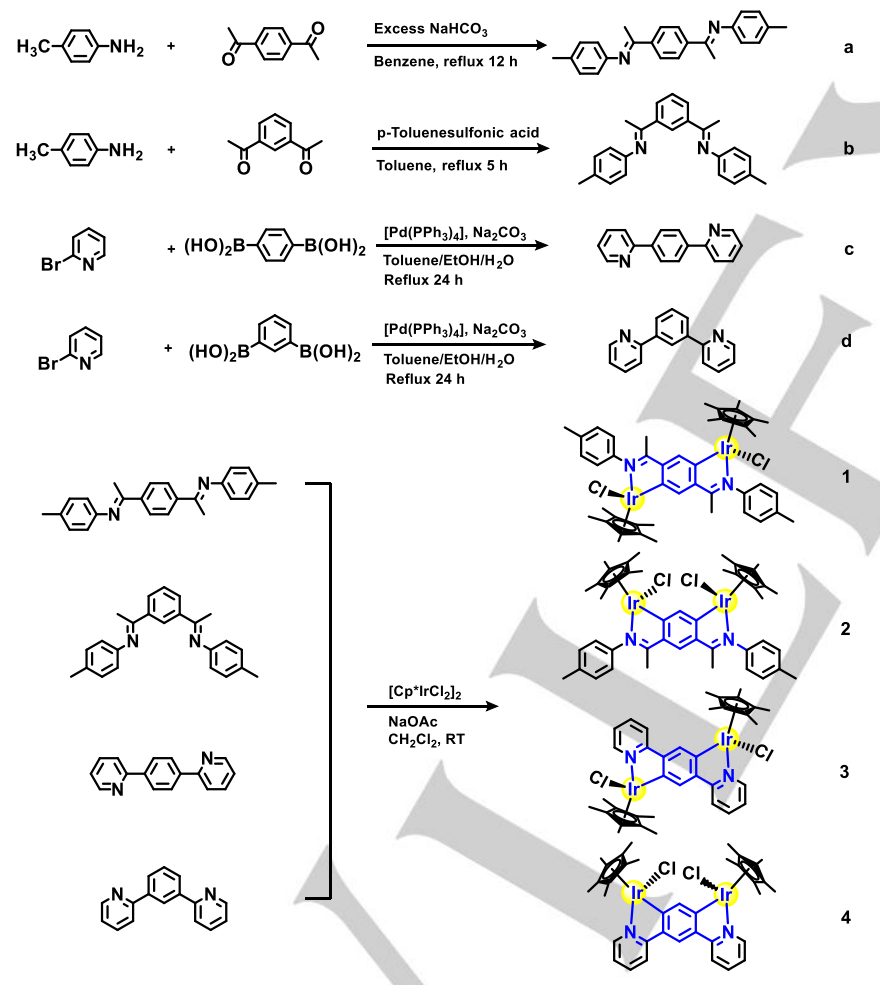

Scheme 1. Synthetic routes toward ligands a-d and complexes 1-4.

\section{Crystal Structures}

Single crystals of complexes $\mathbf{1}, 2$ and $\mathbf{4}$ suitable for $\mathrm{X}$-ray diffraction analysis were grown by slow diffusion of $n$-hexane into the dichloromethane solution of the corresponding complex. The molecular structures (including top and side views) of 1, 2

and 4 are shown in Figure 1. Details of data collection and refinement are given in Table $S 1$ (Supporting Information). Selected parameters (bond lengths $(\AA)$ and angles (deg)) from the crystal structures of 1, 2 and $\mathbf{4}$ are presented in Tables S2S4 (Supporting Information), respectively. In 4, the diiridiumfused tricyclic core displays nearly perfect planarity; the $\mathrm{Ir}-\mathrm{Cl}$ bonds are anti-parallel and almost perpendicular to the iridacycle. Molecular structures of $\mathbf{1}$ and $\mathbf{2}$ are similar to that of $\mathbf{4}$, with the unique difference that the $p$-tolyl rings are highly rotated out of the plane of the conjugated core. Differently from 2 and $\mathbf{4}$, the structure of $\mathbf{1}$ is centrosymmetric. The $\mathrm{Ir}-\mathrm{C}$ and $\mathrm{Ir}-\mathrm{N}$ bond lengths (see Figure 1 and Tables S2-S4 in Supporting Information) are similar to those reported in the literature for related cyclometalated iridium(III) complexes. ${ }^{31-32,34-35,38-40}$ The sum of the internal angles in the five-membered iridacycles in complexes 1, 2 and 4 is $540.0^{\circ} / 540.0^{\circ}, 540.0^{\circ} / 539.6^{\circ}$ and $539.2^{\circ} / 539.9^{\circ}$, respectively. This is an additional evidence for their planarity considered as a fundamental precondition for a strong conjugation and electronic interaction through thre bridge core. As shown in Tables S2-S4 (Supporting Information), the selected bond lengths and angles from DFT-optimized model structures of 1,2 and 4 are very close to the experimental crystal structure data. Complex 1 is centrosymmetric while the molecules of $\mathbf{2}$ and $\mathbf{4}$ have a $\mathrm{C}_{2}$ axis of symmetry along the direction of $\mathrm{C} 1-\mathrm{C} 4$. After one-electron oxidation, the structure of $1^{+}$remains centrosymmetric, with slightly changed bond lengths and angles compared to the neutral precursor, this suggest an electron-delocalized structure of cation $\mathbf{1}^{+}$. However, the bonding situation in singly oxidized $\mathbf{2}^{+}$and $4^{+}$is strongly different compared to $\mathbf{1}^{+}$. For example in $\mathbf{2}^{+}$, the Ir1-C6, Ir1-N1, Ir1$\mathrm{Cl} 1$ and $\mathrm{C} 7-\mathrm{N} 1$ bond lengths are 2.001, 2.113, 2.459 and 1.306 $\AA$ A, respectively, while Ir2-C2, Ir2-N2, Ir2-Cl2 and C26-N2 deviate from their counterparts, being 2.029, 2.074, 2.376 and $1.323 \AA$, respectively. This comparison signals a loss of $\mathrm{C}_{2}$ symmetry in the structure of $\mathbf{2}^{+}$due to more localized charge distribution and spin density residing at one side of the cation. The same asymmetric bonding situation is encountered in $\mathbf{4}^{+}$.

a

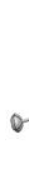

c

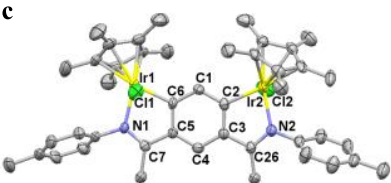

e

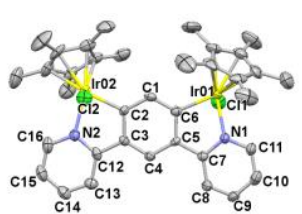

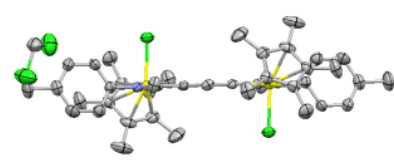

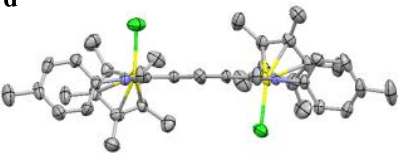

f

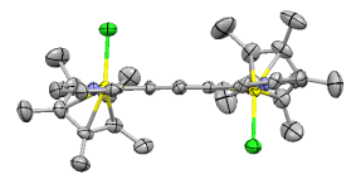

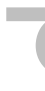


Figure 1. X-ray structures of complexes 1 ( $a$ and b), 2 (c and d) and 4 (e and f) with thermal ellipsoids at the $50 \%$ probability level; a, c and e - top views, b, $\mathrm{d}$ and $\mathrm{f}$ - side views. Atom colour code: carbon - gray; nitrogen - blue; chlorine - green; iridium - yellow. All hydrogen atoms have been omitted for clarity. Selected bond lengths $[\AA]$ for 1: Ir1A-C3A 2.030, Ir1A-N1A 2.082; Selected bond lengths $[\AA]$ for 2, Ir1-N1 2.083, Ir1-C6 2.015, Ir2-N2 2.081, Ir2-C2 2.024; Selected bond lengths $[\AA]$ for 3 : Ir1-N1 2.083, Ir1-C6 2.024, Ir2-C2 2.029, Ir2-N2 2.077.

\section{Electrochemical Oxidation}

Different degrees of electronic interaction between the two metal centres in the studied cyclometalated diiridium complexes was first revealed by cyclic voltammetry (CV) and square-wave voltammetry (SWV). The cyclic and square-wave voltammograms of complexes 1-4 and the corresponding bridging ligands $\mathbf{a}-\mathbf{d}$, which are redox-silent in the relevant potential range, are shown in Figure 2 and Figures S1-S3 (Supporting Information). All four diiridium complexes display two consecutive one-electron oxidation processes. The detailed electrochemical data are summarized in Table 1. They feature a large comproportionation constant $K_{\mathrm{c}}$ for the formally metal-

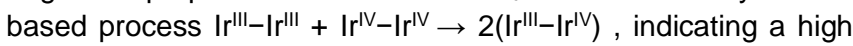
thermodynamic stability of the mixed-valence state. The reality is however different. De facto, the bridging ligands are also strongly involved in the oxidation (see the theoretical DFT section). The standard electrode potential splitting $\Delta E_{1 / 2}$ for the one-electron oxidations involving the two bridged $\operatorname{Ir}(\mathrm{III})$ centres is distinctly larger (by $70 \mathrm{mV}$ ) for trans-Ir2 isomers $\mathbf{1}$ and $\mathbf{3}$ compared to cis-Ir2 isomers 2 and $\mathbf{4}$ (Table 1). This observation points to stronger electronic coupling between the iridacycle halves in $\mathbf{1}$ and $\mathbf{3}$ compared to $\mathbf{2}$ and $\mathbf{4}$. The role of the bridging core in mediating the intermetallic interaction will be discussed in the theoretical section. Importantly, the different iminoethyl and pyridyl components of the bridge in the couples $1 / 2$ and $3 / 4$, respectively, have only a limited impact on the potential values of the formal iridacycle oxidations. Notably, both anodic steps are fully reversible and well-defined for complex 2 (Figure 2). Stable monocations are also observed for 1, 3 and $\mathbf{4}$ (Figure S2, Supporting Information). On the other hand, the subsequent oxidation of $1^{+}, 3^{+}$and $4^{+}$under ambient conditions produces unstable dications as testified by the corresponding cyclic voltammograms in Figure 2 and Figure S3 (Supporting Information). Also the stability of $\mathbf{2}^{2+}$ is only confined to the short time scale of cyclic voltammetry, as revealed by the follow up spectroelectrochemical studies described in the next section.

Table 1. Electrochemical Data for Complexes 1-4 in Dichloromethane/n-Bu${ }_{4} \mathrm{NPF}_{6}{ }^{a}$

\begin{tabular}{cccc}
\hline Complex & $E_{1 / 2}^{(1)}(\mathrm{V})$ & $E_{1 / 2}^{(2)}(\mathrm{V})$ & $\Delta E_{1 / 2}(\mathrm{mV})^{b}$ \\
\hline $\mathbf{1}$ & 0.29 & 0.63 & 340 \\
$\mathbf{2}$ & 0.32 & 0.59 & 270 \\
$\mathbf{3}$ & 0.28 & 0.60 & 320 \\
\hline
\end{tabular}

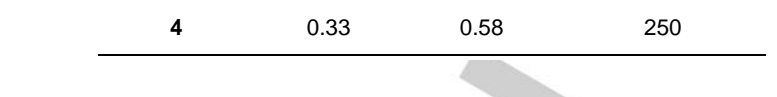

a Electrode potentials are reported vs the standard ferrocene/ferrocenium $\left(\mathrm{Fc} / \mathrm{Fc}^{+}\right)$couple. ${ }^{b} \Delta E_{1 / 2}=E_{1 / 2}{ }^{(2)}-E_{1 / 2}{ }^{(1)}$.

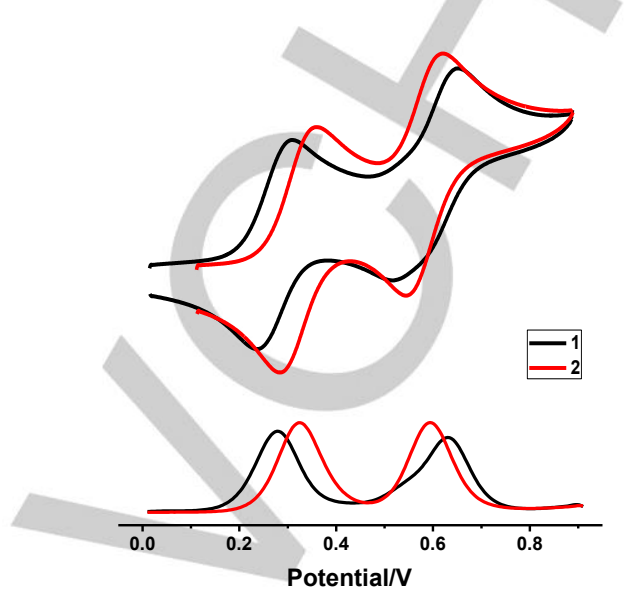

Figure 2. Cyclic voltammograms (top) and anodic square-wave voltammograms (bottom) of complexes 1 and 2 in $\mathrm{CH}_{2} \mathrm{Cl}_{2} / \mathrm{n}-\mathrm{Bu}_{4} \mathrm{NPF}_{6}$ at $v=$ $100 \mathrm{mV} \mathrm{s}^{-1}$. The potential scale corresponds to the standard ferrocene/ferrocenium redox couple.

\section{Anodic UV-vis-NIR and SWIR-IR Spectroelectrochemistry}

Spectroelectrochemical studies of 1-4 were carried out to measure electronic absorption of the stable monooxidized forms and unravel differences in bonding properties between the two isomer pairs. The UV-vis-NIR spectral changes accompanying the one-electron oxidation of 1-4 within an OTTLE cell are shown in Figure 3. Yellow dichloromethane solutions of neutral parent cis-Ir2 complexes 2 and $\mathbf{4}$ reveal strong near-UV absorptions at 360-370 $\mathrm{nm}$ tailing to the visible region, with a shoulder at $450 \mathrm{~nm}$ for 2; no visible absorbance is detected below $450 \mathrm{~nm}$. On the other hand, the dichloromethane solution of trans-Ir2 complex $\mathbf{1}$ is red, which is attributed to two transitions at $555 \mathrm{~nm}(\mathrm{H} \rightarrow \mathrm{L})$ and $434 \mathrm{~nm}(\mathrm{H}-1 \rightarrow \mathrm{L})$ having a partial MLCT character - see Table S5 (Supporting Information) and the following theoretical section. Orange trans-Ir2 complex 3 exhibits the same lowest MLCT $(\mathrm{H} \rightarrow \mathrm{L})$ absorption at $500 \mathrm{~nm}$, while the more intense one at $403 \mathrm{~nm}$ arises from $\mathrm{H} \rightarrow \mathrm{L}+2$ and $\mathrm{H} \rightarrow \mathrm{L}+3$ excitations.

Apart from the isosbestic spectral changes in the near-UV region, which are characteristic for each complex 1-4, the most important information from the spectroscopic monitoring of the reversible first oxidation is obtained in the visible-NIR (Figure 3) and SWIR (Figure 4) region. Starting with trans-Ir2 complex 1 , the two medium-intensity MLCT bands between $400-600 \mathrm{~nm}$ are replaced by a new set at 446 and $572 \mathrm{~nm}$. As revaled by TD DFT calculations presented in the next section, the optical excitation at $572 \mathrm{~nm}$ has hardly any charge transfer character, originating mainly in the delocalized $\pi$-system of the iridacycles and the central benzene ring. Differently from parent $\mathbf{1}$, the monocationic product exhbitis two distinct electronic absorptions 
in the NIR and SWIR region. The higher one at $995 \mathrm{~nm}$ combines electron transfer from the $\mathrm{Cp}^{*}$-iridacycles and their $\mathrm{p}$ tolyl substituents to the central benzene ring of the bridge. A similar charge transfer, $\mathrm{Cp}^{*} \mathrm{Ir}$ to the benzene core, is affiliated with the lowest two excitations seen as an absorption band of medium intensity with a maximum at $2270 \mathrm{~nm}$. The same electron donor and acceptor moieties, $\mathrm{Cp}^{*} \mathrm{IrCl}$ and the benzene core, respectively, participate in the characteristic chargetransfer electronic excitation of trans-Ir2 complex $\mathbf{3}^{+}$in the NIRSWIR region, which is shifted to a slightly higher energy compared to $\mathbf{1}^{+}$. The weak electronic absorption of $3^{+}$between $400-600 \mathrm{~nm}$ involves more the conjugated $\pi^{*}$ system of the planar pyridylbenzene moiety. The minor differences seen in the visible NIR-SWIR spectral region refllect similar chromophores involved in both trans-Ir2 cationic complexes despite the different 1,4-substituents at the benzene core of the bridging ligands, and the same kind of spin-delocalized $\pi$-bonding with a strong participation of the whole metalated bridging ligand and both Ir centres (Chart 1).

The electronic absorption of oxidized cis-Ir2 isomers $\mathbf{2}^{+}$ and $\mathbf{4}^{+}$in the NIR-SWIR region is weak and lacking the pronounced well-defined charge-transfer bands encountered for trans-Ir2 isomers $\mathbf{1}^{+}$and $\mathbf{3}^{+}$(Figure 3 ). The poorly resolved NIR absorption of $\mathbf{2}^{+}$and $\mathbf{4}^{+}$is tailing down to 2500 and $4000 \mathrm{~cm}^{-1}$ (4000 and $2500 \mathrm{~nm}$ ), respectively (Figure 4). The electronic absorption in the SWIR region of both cis-Ir2 cations most likely belongs to IVCT transitions between the Cp*Ir centres due to the highly asymmetric frontier $\beta$-spin orbitals involved in the optical excitation, as revealed by the calculated data presented in the following section. The 1,3-disubstituted benzene core of the bridge also strongly participates in these electron transfers. Cation $\mathbf{4}^{+}$further exhibits two weak electronic absorptions with maxima at 1300 and $699 \mathrm{~nm}$ (Figure 3). The former one involves at least three different excitations that originate from different asymmetric spin-orbitals localized at the same $\mathrm{Cp}^{*}$-iridacycle or involving one of the delocalized planar pyridylbenzeneiridacycle-Cp* chromophores (see the next section). The latter visible absorption of $\mathbf{4}^{+}$is ascribed to two electronic excitations from less asymmetric spin-orbitals encompassing the whole planar bis(pyridyl)benzene backbone and one dominant $\mathrm{Cp}^{*} \mathrm{Ir}$ centre. This visible absorption has its equivalent in the electronic absorption of $\mathbf{2}^{+}$at $753 \mathrm{~nm}$, where the $\mathrm{N}$-p-tolyl substituents participate instead of the pyridyl rings in $4^{+}$. The assignment of the weak NIR absorption of $\mathbf{2}^{+}$is even less straightforward than in the case of $\mathbf{4}^{+}$due to the participation of diverse, variously delocalized, asymmetric spin orbitals.

Complexes 1 and 3 were also oxidized chemically with 1 equiv of tris(4-bromophenyl)aminium hexachloridoantimonate $\left(\mathrm{TBA}^{+} \mathrm{SbCl}_{6}{ }^{-}\right): E_{1 / 2}\left(\mathrm{TBA}^{+} / \mathrm{TBA}\right)=0.70 \mathrm{~V}$ vs $\mathrm{Fc} / \mathrm{Fc}^{+}$(Figure S4, Supporting Information). The electronic absorption of reduced TBA is seen as a rising strong band at $305 \mathrm{~nm}$ (Figure S5, Supporting Information). Apart from that, the observed spectral changes in the UV-vis-NIR region are in full accordance with the aforementioned spectroelectrochemical experiments. The oneelectron oxidation of 1-4 was also monitored in the fingerprint IR spectral region of $1600-1500 \mathrm{~cm}^{-1}$ (Figures S6-S9, Supporting Information). The pairs of the neutral cis- and trans-isomers can readily by distinguished from each other, although a detailed analysis of the vibrational modes in this region was not performed. All four stable cationic complexes show a new weak IR absorption band between 1520 and $1560 \mathrm{~cm}^{-1}$.

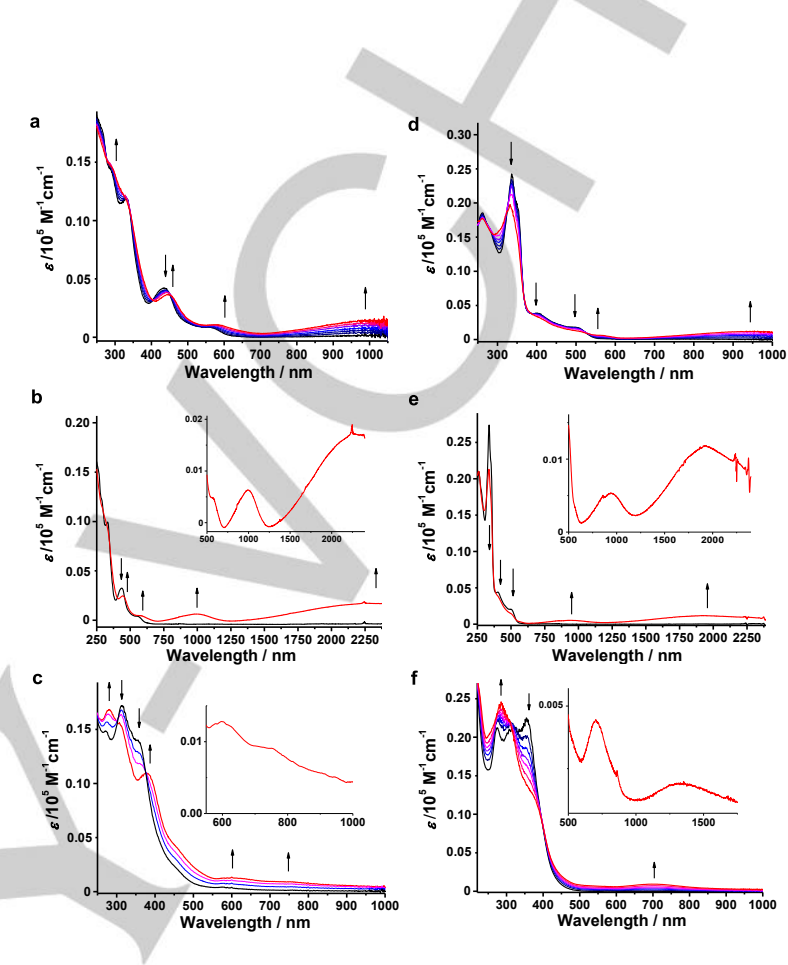

Figure 3. Electronic absorption changes in the UV-vis-NIR-SWIR region recorded during the reversible oxidation in an OTTLE cell: $\mathbf{1} \rightarrow \mathbf{1}^{+}(\mathrm{a}, \mathrm{b}), \mathbf{2} \rightarrow$ $\mathbf{2}^{+}(\mathrm{c}), \mathbf{3} \rightarrow \mathbf{3}^{+}(\mathrm{d}, \mathrm{e}), \mathbf{4} \rightarrow \mathbf{4}^{+}(\mathrm{f})$. Conditions: dichloromethane/n-Bu $4 \mathrm{NPF} 6, T=$ $293 \mathrm{~K}$.
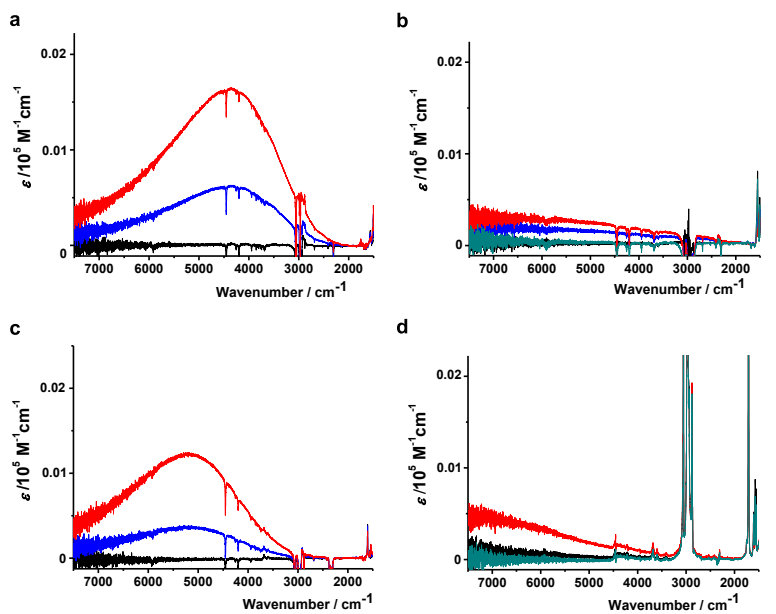

Figure 4. SWIR-IR spectral changes during the reversible oxidation in an OTTLE cell: $\mathbf{1} \rightarrow \mathbf{1}^{+}(\mathrm{a}), \mathbf{2} \rightarrow \mathbf{2}^{+}$(b), $\mathbf{3} \rightarrow \mathbf{3}^{+}(\mathrm{c}), \mathbf{4} \rightarrow \mathbf{4}^{+}(\mathrm{d})$. Black spectrum before the oxidation; blue spectrum - during the oxidation; red spectrum after the oxidation; green spectrum - after the back reduction. Conditions: dichloromethane/n-Bu4NPF,$T=293 \mathrm{~K}$. 


\section{DFT and TD-DFT calculations}

According to DFT calculations carried out on the neutral parent complexes, the symmetric HOMOs of trans-Ir2 isomers $\mathbf{1}$ and $\mathbf{3}$ are mainly distributed over the iridium atoms and the central benzene ring (Figure S10, Supporting Information) while the HOMOs of cis-Ir2 isomers $\mathbf{2}$ and $\mathbf{4}$ tend to delocalize over the whole $\pi$-system of the molecule (Figure S11, Supporting Information). Red-colored $\mathbf{1}$ and $\mathbf{3}$ display a smaller HOMOLUMO gap compared to orange/yellow 2 and $\mathbf{4}$ (Table S5, Supporting Information). The lowest visible electronic absorption of 1 and 3 indeed originates exclusively from the $\mathrm{HOMO} \rightarrow$ LUMO excitation having an MLCT/XLCT $(\mathrm{X}=\mathrm{Cl})$ character, whilst a multicomponent optical excitation is behind the hypsochromic shift observed for 2 and 4 (Table S5, Supporting Information).

Comparative Figure 5 and Figure S12 (Supporting Information) document that there are conspicuous differences in the distribution of spin density between the isomeric pairs $\mathbf{1}^{+/ 3^{+}}$ and $\mathbf{2}^{+} / \mathbf{4}^{+}$. In particular, trans-Ir2 isomers $\mathbf{1}^{+}$and $\mathbf{3}^{+}$feature highly delocalized electronic structures with the spin density distributed symmetrically over the molecular backbone, including both iridium centres (contributions of 0.256 for $\mathbf{1}^{+}$, and 0.254 for $\mathbf{3}^{+}$) and the benzene bridge. In contrast, cis-Ir2 isomers $2^{+}$and $4^{+}$ exhibit highly asymmetric spin density distributions, as testified by the very different values at the two iridium centres, viz. $0.473 / 0.008$ for $2^{+}$and $0.501 / 0.002$ for $4^{+}$. The smaller $\Delta E_{1 / 2}$ values for the two-step oxidations of $\mathbf{2}$ and $\mathbf{4}$ compared to $\mathbf{1}$ and 3 (Table 1) may then reflect the effect of the stabilizing highly symmetric delocalization of the spin density in the singly oxidized trans-isomers. A weaker electronic interaction between the formally $\operatorname{Ir}(\mathrm{III})$ and $\operatorname{Ir}(\mathrm{IV})$ centres in both monocationic cisisomers makes the removal of the second electron more thermodynamically feasible.
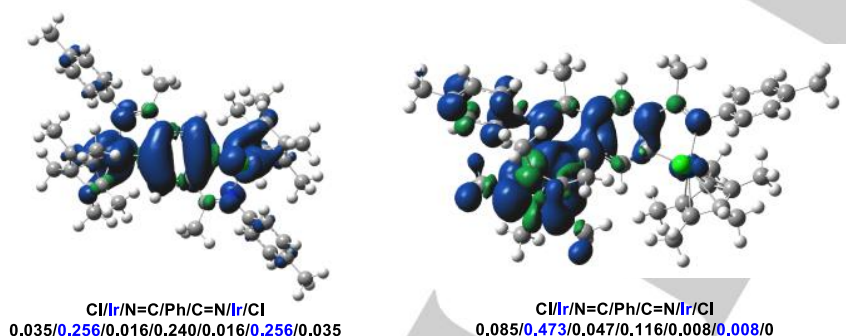

$0.035 / 0.256 / 0.016 / 0.240 / 0.016 / 0.256 / 0.035$

Figure 5. The delocalized and localized spin density distribution in $\mathbf{1}^{+}$(left) and $\mathbf{2}^{+}$(right), respectively, with the corresponding contributions of different parts. Contour values: $\pm 0.04\left(\mathrm{e} / \mathrm{bohr}^{3}\right)^{1 / 2}$.

Table 2. TD-DFT calculated and experimental electronic absorption of $\mathbf{1}^{+-} \mathbf{4}^{+}$.

\begin{tabular}{|c|c|c|c|c|}
\hline Complex & Excitation (percentage) & $f$ & $\lambda_{\max }($ calc $) / \mathrm{nm}$ & $\begin{array}{c}\lambda_{\max }(\exp ) / \mathrm{nm} \\
\left(\varepsilon / 10^{5} \mathrm{M}^{-1} \mathrm{~cm}^{-1}\right)\end{array}$ \\
\hline \multirow{4}{*}{$1^{+}$} & $\beta$-HOSO $\rightarrow \beta$-LUSO (88\%) & 0.132 & 1865 & \multirow{2}{*}{$2270(0.017)$} \\
\hline & $\beta$-HOSO-2 $\rightarrow \beta$-LUSO (87\%) & 0.156 & 1105 & \\
\hline & $\beta$-HOSO- $4 \rightarrow \beta$-LUSO (19\%) & & \multirow[b]{2}{*}{821} & \multirow[b]{2}{*}{$995(0.006)$} \\
\hline & $\beta$-HOSO- $6 \rightarrow \beta$-LUSO $(73 \%)$ & 0.017 & & \\
\hline
\end{tabular}

\begin{tabular}{|c|c|c|c|c|}
\hline & $\beta$-HOSO-4 $\rightarrow \beta$-LUSO (76\%) & & & \\
\hline & $\beta$-HOSO- $6 \rightarrow \beta$-LUSO $(20 \%)$ & 0.01 & $1<T$ & \\
\hline & $\beta$-HOSO-12 $\rightarrow \beta$-LUSO (47\%) & 0.003 & 572 & $585(0.005)$ \\
\hline \multirow{11}{*}{$2^{+}$} & $\beta$-HOSO $\rightarrow \beta$-LUSO (95\%) & 0.016 & 2271 & unresolved \\
\hline & $\beta$-HOSO- $5 \rightarrow \beta$-LUSO $(28 \%)$ & & & \\
\hline & $\beta$-HOSO-2 $\rightarrow \beta$-LUSO $(17 \%)$ & 0.013 & 1212 & unresolved \\
\hline & $\beta$-HOSO- $1 \rightarrow \beta$-LUSO $(25 \%)$ & & & \\
\hline & $\beta$-HOSO-4 $\rightarrow \beta$-LUSO $(27 \%)$ & & 853 & \\
\hline & $\beta$-HOSO-2 $\rightarrow \beta$-LUSO (42\%) & & 853 & unresolved \\
\hline & $\beta$-HOSO-6 $\rightarrow \beta$-LUSO (23\%) & & & \multirow{5}{*}{$753(0.009)$} \\
\hline & $\beta$-HOSO- $4 \rightarrow \beta$-LUSO $(40 \%)$ & 0.048 & 735 & \\
\hline & $\beta$-HOSO- $2 \rightarrow \beta$-LUSO $(19 \%)$ & & & \\
\hline & $\beta$-HOSO- $6 \rightarrow \beta$-LUSO $(38 \%)$ & \multirow{2}{*}{0.019} & \multirow{2}{*}{699} & \\
\hline & $\beta$-HOSO-4 $\rightarrow \beta$-LUSO (20\%) & & & \\
\hline \multirow{4}{*}{$3^{+}$} & $\beta$-HOSO $\rightarrow \beta$-LUSO (83\%) & 0.137 & 1535 & \multirow{2}{*}{$1923(0.012)$} \\
\hline & $\beta$-HOSO- $\rightarrow \beta$-LUSO $(82 \%)$ & 0.168 & 1085 & \\
\hline & $\beta$-HOSO- $5 \rightarrow \beta$-LUSO $(92 \%)$ & 0.010 & 761 & $940(0.005)$ \\
\hline & $\alpha$-HOSO $\rightarrow$ a-LUSO (77\%) & 0.033 & 500 & $564(0.004)$ \\
\hline \multirow{10}{*}{$4^{+}$} & $\beta$-HOSO $\rightarrow \beta$-LUSO (95\%) & 0.015 & 2804 & unresolved \\
\hline & $\beta$-HOSO-2 $\rightarrow \beta$-LUSO $(59 \%)$ & 0.021 & 1604 & \multirow{6}{*}{$1330(0.002)$} \\
\hline & $\beta$-HOSO-4 $\rightarrow \beta$-LUSO (25\%) & \multirow{3}{*}{0.023} & \multirow{3}{*}{896} & \\
\hline & $\beta$-HOSO-3 $\rightarrow \beta$-LUSO $(40 \%)$ & & & \\
\hline & $\beta$-HOSO-2 $\rightarrow \beta$-LUSO $(21 \%)$ & & & \\
\hline & $\beta$-HOSO-4 $\rightarrow \beta$-LUSO $(27 \%)$ & \multirow{2}{*}{0.020} & \multirow{2}{*}{825} & \\
\hline & $\beta$-HOSO-3 $\rightarrow \beta$-LUSO $(53 \%)$ & & & \\
\hline & $\beta$-HOSO- $6 \rightarrow \beta$-LUSO $(54 \%)$ & \multirow{2}{*}{0.053} & \multirow{2}{*}{744} & \multirow{3}{*}{$699(0.005)$} \\
\hline & $\beta$-HOSO-4 $\rightarrow \beta$-LUSO (24\%) & & & \\
\hline & $\beta$-HOSO- $5 \rightarrow \beta$-LUSO (70\%) & 0.050 & 646 & \\
\hline
\end{tabular}

The electronic absorption spectra of $\mathbf{1}^{+}-\mathbf{4}^{+}$provide important information about their bonding properties. To understand the different visible-NIR and SWIR absorption spectra of transisomers $\mathbf{1}^{+} / \mathbf{3}^{+}$and cis-isomers $\mathbf{2}^{+} / \mathbf{4}^{+}$, TD-DFT calculations were also performed on optimized models of the four monocations. The corresponding isosurface plots of the molecular orbitals involved in the major electronic excitations are displayed in Figures 6 and 7. The electronic absorptions obtained from the TD-DFT calculations (Table 2 ) on $\mathbf{1}^{+}$and $\mathbf{3}^{+}$comply well with the experimental visible-NIR-SWIR spectra. The broad absorption band of $1^{+}$between $7000-2500 \mathrm{~cm}^{-1}(1400-4000 \mathrm{~nm})$ can be assigned to the electronic absorptions calculated at 1105 and $1864 \mathrm{~nm}$, which correspond to the $\beta$-HOSO-2 $\rightarrow \beta$-LUSO (87\%) $\pi$-excitation between the iridacycles and the central benzene ring (MLCT), and the $\pi$-delocalized $\beta$-HOSO $\rightarrow \beta$-LUSO (88\%) transition. The experimental absorption of $\mathbf{1}^{+}$between $700-$ $1250 \mathrm{~nm}$, with a maximum at $995 \mathrm{~nm}$, is attributed to the calculated mixed ILET and MLCT electronic transitions at 821 and $727 \mathrm{~nm}$ ( $\beta$-HOSO- $4 / \beta$-HOSO- $6 \rightarrow \beta$-LUSO). Finally, the weak visible absorption of $\mathbf{1}^{+}$at $585 \mathrm{~nm}$ has its calculated counterpart at $572 \mathrm{~nm}$, with a dominant contribution from $\beta-\mathrm{HOSO}-12 \rightarrow \beta$ - 
LUSO $(47 \%)$ localized at the $\pi$-orbital system of the molecular backbone. The situation is similar for $3^{+}$but the corresponding electronic absorptions shift to a higher energy. The calculated optical excitations of $3^{+}$at 1535 and $1085 \mathrm{~nm}$ are responsible for the broad intense absorption between $8000-2500 \mathrm{~cm}^{-1}$ (1200 $4000 \mathrm{~nm}$ ). The calculated absorption at $761 \mathrm{~nm}$ then belongs to the experimental absorption between $650-1200 \mathrm{~nm}$, which is attributed to the $\beta$-HOSO-5 $\rightarrow \beta$-LUSO (92\%) MLCT process. The calculated absorption at $500 \mathrm{~nm}$ can be attributed to the $\alpha$ HOSO $\rightarrow$ a-LUSO (77\%) transition that corresponds to the experimental absorption at $565 \mathrm{~nm}$ having a partial MLCT character. Remarkably, frontier spin orbitals of $\mathbf{1}^{+}$and $3^{+}$are all distributed symmetrically. The absorption bands of these transIr2 monocations in the NIR and SWIR region are thus attributed to combined MLCT/ILET/IL processes instead of IVCT.

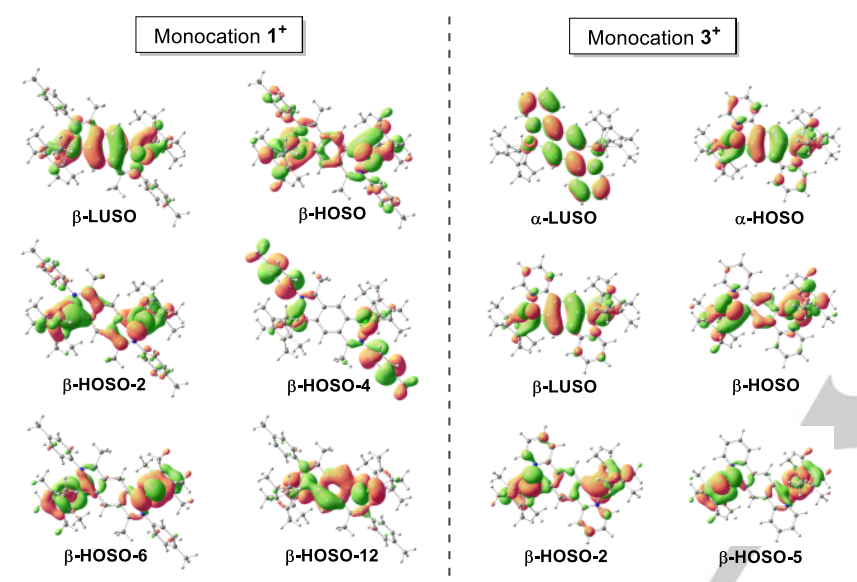

Figure 6. Isosurface plots of molecular orbitals involved in the major electronic excitations in $\mathbf{1}^{+}$(left) and $\mathbf{3}^{+}$(right).

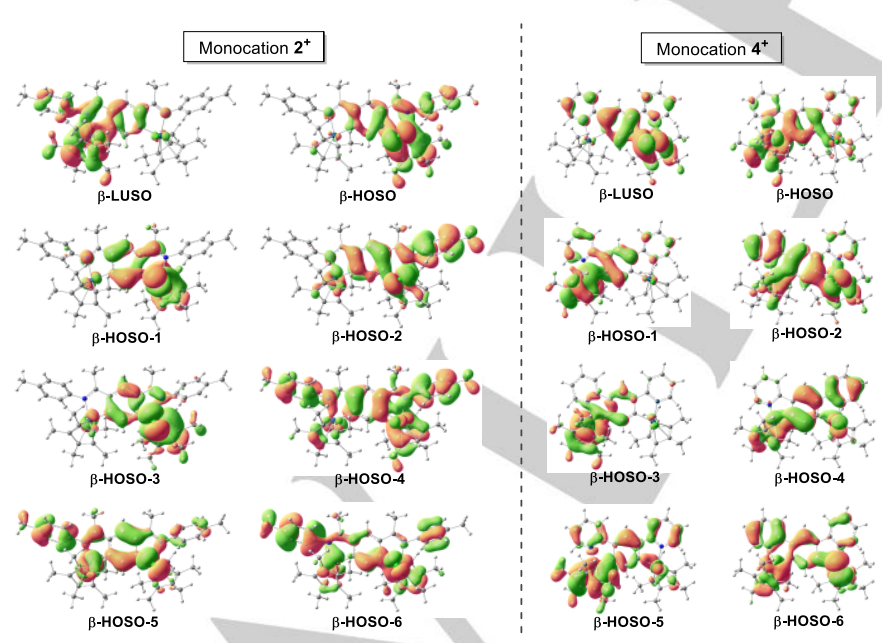

Figure 7. Isosurface plots of molecular orbitals involved in the major electronic excitations calculated for $\mathbf{2}^{+}$(left) and $\mathbf{4}^{+}$(right).

In contrast to the singly oxidized trans-Ir2 isomers, the poorly resolved $\beta$-HOSO $\rightarrow \beta$-LUSO transitions of $\mathbf{2}^{+}$and $\mathbf{4}^{+}$in the SWIR region (Table 2 ) exhibit an IVCT character. For $\mathbf{2}^{+}$, the calculated strongest visible absorption at $735 \mathrm{~nm}$ supplemented with another one at $853 \mathrm{~nm}$ most likely correspond to the experimental bands near 600 and $750 \mathrm{~nm}$. The weak NIR-SWIR electronic absorptions calculated at 1212 and $2271 \mathrm{~nm}$ are also preceptible in the experimental spectrum. Similarly, for $\mathbf{4}^{+}$, the calculated moderately strong absorptions at 646 and $744 \mathrm{~nm}$ most likely correspond to the experimental band at $699 \mathrm{~nm}$. The calculated weaker absorptions at 825, 895 and $1604 \mathrm{~nm}$ correspond well with the recorded broad NIR absorption showing a maximum at $1330 \mathrm{~nm}$ (Figure $3 \mathrm{f}$, inset).

\section{Conclusions}

To summarize, we report successful syntheses and full characterization of four redox-responsive cyclometalated diiridium complexes, 1-4. Crystal structures of 1, 2 and 4 were resolved by single-crystal X-ray diffraction. The diiridium-fused polycycles in these complexes are co-planar, which provides a fundamental condition for strong $\pi$-conjugation and intramolecular charge transfer. All complexes display two consecutive one-electron oxidation processes but only the first one is fully reversible. The smaller $\Delta E_{1 / 2}$ values for the cisisomers $(2,4)$ compared to the trans-isomers $(\mathbf{1}, \mathbf{3})$ reflect weaker electronic coupling between the two iridium centres in the electronically asymmetric (mixed-valence) cis-Ir2 monocations. For $\mathbf{1}^{+}$and $\mathbf{3}^{+}$, the distribution of the spin density is symmetric and strongly delocalized over the conjugated $\pi-$ system of the molecular backbone. TD-DFT calculations of the latter monocations have revealed intramolecular charge transfer (MLCT and ILET) excitations matching well with the reasonably strong electronic absorption in the NIR and SWIR region. In contrast, mixed-valence cis-isomers $\mathbf{2}^{+}$and $4^{+}$show much weaker IVCT electronic transitions in the SWIR region. The different mutual orientation of the two iridacycles at the central benzene ring has thus pronounced consequences for the anodic behavior, spin density distribution and the nature of low-energy electronic transitions. This work therefore provides a strong stimulus for continued investigations of newly designed cyclometalated diiridium complexes in order to achieve deeper understanding of their electronic properties, especially the consequences of cyclometallation on electronic communication between metal centres, and for further exploration of their applicability in molecular electronic devices.

\section{Experimental Section}

\section{General Materials}

All manipulations were carried out under an atmosphere of dry argon (or nitrogen) gas by using standard Schlenk techniques, unless stated otherwise. Dichloromethane for reactions was distilled from calcium hydride under $\mathrm{N}_{2}$ prior to use. Toluene and ethanol used for SuzukiCoupling reactions was not distilled but degassed by bubbling with argon before use. Ultradry benzene was purchased commercially. The starting materials $p$-methylaniline, 1,4-diacetylbenzene, 1,3-diacetylbenzene, 1,4phenylenediboronic acid, 1,3-phenylenediboronic acid and 2- 
bromopyridine were commercially available and used without further purification. The catalyst, tetrakis(triphenylphosphine)palladium(0), was prepared according to the literature ${ }^{41}$.

${ }^{1} \mathrm{H}$ and ${ }^{13} \mathrm{C}$ NMR spectra of compounds a-d and complexes 1-4 are presented in Figures S13-S27 (Supporting Information).

Synthesis of 1,4-Bis\{1-[(4-methylphenyl)imino]-ethyl\}benzene (compound a): A mixture of $\mathrm{NaHCO}_{3}(2.28 \mathrm{~g}, 27.1 \mathrm{mmol}), p$ methylaniline $(0.581 \mathrm{~g}, 5.42 \mathrm{mmol}), 1,4$-diacetylbenzene $(0.440 \mathrm{~g}, 2.71$ mmol), activated molecular sieves ( $7 \mathrm{~g} ; 4 \AA$ ) , and benzene $(15 \mathrm{~mL})$ was added to a Schlenk-tube under a nitrogen atmosphere and heated to reflux overnight. The reaction mixture was filtered through Celite that was then washed with $\mathrm{CH}_{2} \mathrm{Cl}_{2}$. The filtrate was collected, the solvent evaporated in vacuo and methanol added to afford a brilliant yellow solid that was washed with methanol and dried in vacuo. Yield: $443 \mathrm{mg}, 48 \%$. ${ }^{1} \mathrm{H} \mathrm{NMR}\left(400 \mathrm{MHz}, \mathrm{CDCl}_{3}\right): \delta 8.03(\mathrm{~s}, 4 \mathrm{H}), 7.18(\mathrm{~d}, J=7.6 \mathrm{~Hz}, 4 \mathrm{H}), 6.72$ (d, $J=8.0 \mathrm{~Hz}, 4 \mathrm{H}), 2.36$ (s, 6H), 2.27 (s, 6H) ppm. ${ }^{13} \mathrm{C}$ NMR $(101 \mathrm{MHz}$, $\left.\mathrm{CDCl}_{3}\right): \delta 165.1,149.0,141.3,132.9,129.7,127.3,119.5,21.0,17.6$ ppm.

Synthesis of 1,3-Bis\{1-[(4-methylphenyl)imino]-ethyl\}benzene (compound b): This compound was prepared by the procedure described in the corresponding literature. ${ }^{37} \mathrm{~A}$ solution of $p$-methylaniline $(1.32 \mathrm{~g}, 12.4 \mathrm{mmol})$ and 1,3-diacetylbenzene $(1.00 \mathrm{~g}, 6.20 \mathrm{mmol})$ in toluene $(20 \mathrm{~mL})$ was treated with $p$-toluenesulfonic acid $(0.2 \mathrm{mg})$ and refluxed for $5 \mathrm{~h}$. During this time, water in the solution was removed using a DeanStark apparatus. The solution was cooled to room temperature and concentrated in vacuo. Methanol was then added to afford a faint yellow solid that was washed with methanol and dried in vacuo. Yield: $45 \%$. ${ }^{1} \mathrm{H}$ NMR $\left(400 \mathrm{MHz}, \mathrm{CDCl}_{3}\right): \delta 8.54(\mathrm{~s}, 1 \mathrm{H}), 8.05$ (d, J $=8.0 \mathrm{~Hz}, 2 \mathrm{H}), 7.52(\mathrm{t}, J=7.6,7.6 \mathrm{~Hz}, 1 \mathrm{H}), 7.16(\mathrm{~d}, J=8.0 \mathrm{~Hz}, 4 \mathrm{H}), 6.71$ (d, $J=8.0 \mathrm{~Hz}, 4 \mathrm{H}), 2.35(\mathrm{~s}, 6 \mathrm{H}), 2.29(\mathrm{~s}, 6 \mathrm{H}) \mathrm{ppm}$. No further characterization was conducted as the ${ }^{1} \mathrm{H}$ NMR spectrum perfectly matched the literature data.

Synthesis of 1,4-di(pyridin-2-yl)benzene (compound c): To a stirred solution of 1,4-phenylenediboronic acid (0.524 g, $3.16 \mathrm{mmol}), \mathrm{Na}_{2} \mathrm{CO}_{3}$ $(2.00 \mathrm{~g}, 18.9 \mathrm{mmol})$, and 2-bromopyridine $(1.00 \mathrm{~g}, 6.33 \mathrm{mmol})$ in toluene $(20 \mathrm{~mL}) /$ ethanol $(10 \mathrm{~mL}) / \mathrm{H}_{2} \mathrm{O}(10 \mathrm{~mL}),\left[\mathrm{Pd}\left(\mathrm{PPh}_{3}\right)_{4}\right](0.074 \mathrm{~g}, 0.064 \mathrm{mmol})$ was added under argon. The reaction mixture was refluxed for $22 \mathrm{~h}$ and then cooled to room temperature. The mixture was extracted with $\mathrm{CH}_{2} \mathrm{Cl}_{2}$, dried over $\mathrm{Na}_{2} \mathrm{SO}_{4}$ and evaporated in vacuo. Subsequent purification by column chromatography (silica gel, PE:EA $=5: 1, \mathrm{v} / \mathrm{v}$ ) afforded a white solid. Yield: $0.570 \mathrm{~g}, 78 \%$. ${ }^{1} \mathrm{H}$ NMR $\left(400 \mathrm{MHz}, \mathrm{CDCl}_{3}\right): \delta 8.73$ (d, $J=4.4$ $\mathrm{Hz}, 2 \mathrm{H}), 8.13(\mathrm{~s}, 4 \mathrm{H}), 7.80(\mathrm{~m}, 4 \mathrm{H}), 7.25$ (d, $J=10 \mathrm{~Hz}, 2 \mathrm{H}) \mathrm{ppm} .{ }^{13} \mathrm{C}$ NMR $\left(101 \mathrm{MHz}, \mathrm{CDCl}_{3}\right): \delta 156.9,149.8,139.8,136.8,127.2,122.3$, 120.6 ppm. El-MS: $\mathrm{m} / \mathrm{z}$ calcd for $\mathrm{C}_{16} \mathrm{H}_{12} \mathrm{~N}_{2}[\mathrm{M}]^{+}: 232.10$, found 232.30 .

Synthesis of 1,3-di(pyridin-2-yl)benzene (compound d): This white, solid compound was prepared according to the same method as for the synthesis of 1,4-di(pyridin-2-yl)benzene, using 1,3-phenylenediboronic acid instead.. Yield: $75 \%$. ${ }^{1} \mathrm{H}$ NMR $\left(400 \mathrm{MHz}, \mathrm{CDCl}_{3}\right)$ : $\delta 8.71$ (d, $J=4.4$ $\mathrm{Hz}, 2 \mathrm{H}$ ), 8.64 (s, $1 \mathrm{H}), 8.05$ (d, $J=7.6 \mathrm{~Hz}, 2 \mathrm{H}), 7.81$ (d, $J=7.5 \mathrm{~Hz}, 2 \mathrm{H}$ ), $7.72(\mathrm{t}, J=7.6,7.6 \mathrm{~Hz}, 2 \mathrm{H}), 7.57(\mathrm{t}, J=7.6,8.0 \mathrm{~Hz}, 1 \mathrm{H}), 7.21(\mathrm{t}, J=5.6$, 5.6, 2H) ppm. $\left.{ }^{13} \mathrm{C} \mathrm{NMR} \mathrm{(101} \mathrm{MHz,} \mathrm{CDCl}_{3}\right): \delta 157.1,149.7,139.9,136.8$, 129.2, 127.5, 125.5, 122.3, 120.7 ppm. El-MS: $m / z$ calcd for $\mathrm{C}_{16} \mathrm{H}_{12} \mathrm{~N}_{2}$ $[\mathrm{M}]^{+}:$232.10, found 232.27 .
General procedure for the preparation of cyclometalated complexes 1-4: A mixture of $\left[\mathrm{Cp}^{*} \mid \mathrm{rCl}_{2}\right]_{2} \quad\left(\mathrm{Cp}^{*}=1,2,3,4,5\right.$-pentamethylcyclopentadiene) (1.05 equiv.), the imine or pyridine-based ligand ( 1 equiv.) $\mathrm{NaOAc}$ (10 equivs) and dichloromethane were stirred at room temperature for $1 \mathrm{~d}$ under nitrogen. The reaction mixture was then filtered through Celite and dried over $\mathrm{MgSO}_{4}$. The solvent was removed under vacuum and the resulting solid was washed with diethyl ether/hexane to afford pure products. Single crystals suitable for $\mathrm{X}$-ray analysis were obtained by diffusion of diethyl ether into a $\mathrm{CH}_{2} \mathrm{Cl}_{2}$ solution of the respective complex.

Complex 1, dark red solid. Yield: $80 \%$. ${ }^{1} \mathrm{H}$ NMR $\left(400 \mathrm{MHz}, \mathrm{CD}_{2} \mathrm{Cl}_{2}\right): \delta$ $7.93(\mathrm{~s}, 2 \mathrm{H}), 7.69(\mathrm{~s}, 2 \mathrm{H}), 7.28(\mathrm{~s}, 4 \mathrm{H}), 6.82(\mathrm{~s}, 4 \mathrm{H}), 2.51(\mathrm{~s}, 6 \mathrm{H}), 2.42(\mathrm{~s}$, 6H) $1.41(\mathrm{~s}, 30 \mathrm{H}) \mathrm{ppm} .{ }^{13} \mathrm{C} \mathrm{NMR}\left(101 \mathrm{MHz}, \mathrm{CD}_{2} \mathrm{Cl}_{2}\right)$ : $\delta$ 181.4, 157.6, 152.0, 148.9, 136.4, 134.9, 123.1, 89.3, 21.1, 17.5, 8.7 ppm. Elemental analysis: Calcd. for $\mathrm{C}_{44} \mathrm{H}_{52} \mathrm{Cl}_{2} \mathrm{I}_{2} \mathrm{~N}_{2}$ (\%): C 49.66, $\mathrm{H}$ 4.92, N 2.63. Found (\%): C 49.85, H 4.63, N 2.84.

Complex 2, orange solid. Yield: $74 \%$. ${ }^{1} \mathrm{H}$ NMR $\left(400 \mathrm{MHz}, \mathrm{CD}_{2} \mathrm{Cl}_{2}\right): \delta$ $8.33(\mathrm{~s}, 1 \mathrm{H}), 7.62(\mathrm{~s}, 1 \mathrm{H}), 7.25$ (d, J = 7.2 Hz, 4H), 2.40 (s, 12H), 1.45 (s, $30 \mathrm{H})$ ppm. ${ }^{13} \mathrm{C} \mathrm{NMR}\left(101 \mathrm{MHz}, \mathrm{CD}_{2} \mathrm{Cl}_{2}\right): \delta 180.8,176.7,148.8,143.3$, 142.6, 136.1, 128.5, 89.8, 21.1, 16.5, 8.7 ppm. Elemental analysis: Calcd. for $\mathrm{C}_{44} \mathrm{H}_{52} \mathrm{Cl}_{2} \mathrm{Ir}_{2} \mathrm{~N}_{2}$ (\%): C 49.66, H 4.92, N 2.63. Found (\%): C 49.47, H $5.27, \mathrm{~N} 2.75$.

Complex 3, red solid. Yield: 92\%. ${ }^{1} \mathrm{H}$ NMR $\left(400 \mathrm{MHz}, \mathrm{CDCl}_{3}\right): \delta 8.71$ (d, $J=5.6 \mathrm{~Hz}, 2 \mathrm{H}), 8.13(\mathrm{~s}, 2 \mathrm{H}), 7.92(\mathrm{~d}, J=8.0 \mathrm{~Hz}, 2 \mathrm{H}), 7.68(\mathrm{~d}, J=7.2 \mathrm{~Hz}$, $2 \mathrm{H}), 7.07(\mathrm{t}, J=6.0,6.8 \mathrm{~Hz}, 2 \mathrm{H}), 1.68(\mathrm{~s}, 30 \mathrm{H}) \mathrm{ppm} .{ }^{13} \mathrm{C} \mathrm{NMR}(101 \mathrm{MHz}$, $\left.\mathrm{CDCl}_{3}\right): \delta 167.4,154.0,151.7,147.6,136.9,130.8,122.2,119.5,88.3$, $9.2 \mathrm{ppm}$. Elemental analysis: Calcd. for $\mathrm{C}_{36} \mathrm{H}_{40} \mathrm{Cl}_{2} \mathrm{Ir}_{2} \mathrm{~N}_{2}$ (\%): C $45.23, \mathrm{H}$ 4.22, N 2.93. Found (\%): C 45.68, H 4.69, N 2.70.

Complex 4, yellow solid. Yield: $88 \%$. ${ }^{1} \mathrm{H}$ NMR $\left(400 \mathrm{MHz}, \mathrm{CDCl}_{3}\right): \delta$ $8.67(\mathrm{~d}, J=4.8 \mathrm{~Hz}, 2 \mathrm{H}), 8.35(\mathrm{~s}, 1 \mathrm{H}), 7.92(1,1 \mathrm{H}), 7.82(\mathrm{~d}, J=7.6 \mathrm{~Hz}$, 2H), 7.60 (t, $J=7.2 \mathrm{~Hz}, 2 \mathrm{H}$ ) 6.99 (d, $J=6.0 \mathrm{~Hz}, 2 \mathrm{H}$ ), 1.71 (s, 30H) ppm. ${ }^{13} \mathrm{C} \mathrm{NMR}\left(101 \mathrm{MHz}, \mathrm{CDCl}_{3}\right): \delta 170.9,167.8,151.3,144.6,138.6,136.7$, 121.1, 118.8, 117.8, 88.9, $9.1 \mathrm{ppm}$. Elemental analysis: Calcd. for $\mathrm{C}_{36} \mathrm{H}_{40} \mathrm{Cl}_{2} \mathrm{r}_{2} \mathrm{~N}_{2}$ (\%): C 45.23, H 4.22, N 2.93. Found (\%): C 45.57, H 4.64, N2.66.

\section{Crystallographic Details}

Single crystals of 1. $\mathrm{CH}_{2} \mathrm{Cl}_{2}, 2$ and 4 were grown by slow diffusion of $n$ hexane into a dichloromethane solution of the complexes. Crystals with approximate dimensions of $0.20 \times 0.20 \times 0.10 \mathrm{~mm}^{3}$ for $1,0.40 \times 0.30 \times$ $0.20 \mathrm{~mm}^{3}$ for 2 and $0.20 \times 0.20 \times 0.15 \mathrm{~mm}^{3}$ for 4 were mounted on glass fibers for diffraction experiments. Intensity data were collected by Bruker APEX-II CCD diffractometer with Mo Ka radiation (0.71073 $\AA$ ) at room temperature. The molecular structures were solved by a combination of intrinsic phasing methods (SHELXT-97) ${ }^{42}$ and Fourier difference techniques and refined with Olex ${ }^{43}$. All non- $\mathrm{H}$ atoms were refined anisotropically; the hydrogen atoms were placed in ideal positions and refined as riding atoms. Further crystal data and details of the data collection are summarized in Table S1 (Supporting Information). Selected bond lengths and angles are presented in Table S2-S4 (Supporting Information). The CCDC numbers for 1, 2, and $\mathbf{4}$ are 1921852, 1921854 and 1921855 , respectively.

\section{Physical Measurements}

${ }^{1} \mathrm{H}$ and ${ }^{13} \mathrm{C}$ NMR spectra (see Supporting Information) were recorded on Varian MERCURY Plus $400 \mathrm{MHz}$ or Bruker AVANCE III HD-400 spectrometers. ${ }^{1} \mathrm{H}$ and ${ }^{13} \mathrm{C}$ NMR chemical shifts are relative to TMS. 
Elemental analyses $(\mathrm{C}, \mathrm{H}, \mathrm{N})$ were performed with a Vario EllII CHNSO instrument. The controlled-potential electrochemical measurements were conducted with a $\mathrm{CHI} 660 \mathrm{C}$ potentiostat $(\mathrm{CHI}$ USA). An air-tight threeelectrode single-compartment cell was used for the solution of complexes and supporting electrolyte in dry $\mathrm{CH}_{2} \mathrm{Cl}_{2}$. The solution was deaerated by bubbling with dry argon on a frit for about 1 min before the measurement. The analyte (complex, ligand) and electrolyte $\left(n-B_{4} N_{2} F_{6}\right)$ concentrations were typically $10^{-3}$ and $10^{-1} \mathrm{~mol} \mathrm{dm}^{-3}$, respectively. A pre-polished 500 $\mu \mathrm{m}$ diameter platinum disk working electrode, a platinum wire counter electrode, and an $\mathrm{Ag}$ coil pseudoreference electrode were used. Spectroelectrochemical experiments at room temperature were performed with an airtight optically transparent thin-layer electrochemical (OTTLE) cell (optical path length of ca. $200 \mu \mathrm{m}$ ) equipped with a Pt minigrid working electrode and $\mathrm{CaF}_{2}$ windows. ${ }^{44}$ The cell was positioned in the sample compartment of a Perkin-Elmer Lambda 900 spectrophotometer (UV-vis-NIR-SWIR region), Scinco S3100 diode array spectrophotometer (UV-vis-NIR region) and Bruker Vertex 70v FT-IR spectrometer (SWIR-IR region). The controlled-potential electrolyses were carried out with an EmStat 3 (PalmSens) potentiostat. The concentration of spectroelectrochemical samples was ca. $3 \times 10^{-3} \mathrm{~mol}$ $\mathrm{dm}^{-3}$. Dry $3 \times 10^{-1} \mathrm{M} \mathrm{n}-\mathrm{Bu}_{4} \mathrm{NPF}_{6}$ was used as the supporting electrolyte. Chemical oxidation of parent complexes to corresponding stable monocations and unstable dications was achieved by adding equivalent amounts of tris(4-bromophenyl)aminium hexachloridoantimonate, $\mathrm{TBA}^{+} \mathrm{SbCl}_{6}^{-}$, in dichloromethane.

\section{Computational Details}

DFT calculations were performed using the Gaussian 09 software ${ }^{45}$ at the B3LYP/6-31G* (Lanl2dz for the iridium atom) level of theory. Geometry optimizations and full geometry were performed without any symmetry constraints; frequency calculations on the resulting optimized geometries showed no imaginary frequencies. Electronic transitions were calculated by the time-dependent DFT (TD-DFT) method. The molecular orbital contributions were generated using GaussView 5.0. The solvation effects in dichloromethane were included for a part of the calculations with the CPCM. ${ }^{46}$

\section{Supporting Information}

Crystallographic details, supplementary voltammetric and spectroelectrochemical records and data, supplementary DFT and TD-DFT data, NMR spectra. AUTHOR INFORMATION

\section{ORCID}

František Hartl: 0000-0002-7013-5360

\section{Notes}

The authors declare no competing financial interest.

\section{Acknowledgements}

The authors gratefully acknowledge the financial support from the National Natural Science Foundation of China (Grant No. 21772054), and the 111 Project B17019 (F.H.). Experimental work at the University of Reading was funded by Spectroelectrochemistry Reading, a spinout company.

Keywords: Diiridium Complex • Cyclometalated Isomers • Cyclic Voltammetry $\cdot$ Spectroelectrochemistry $\cdot$ Mixed-valence State

[1] J.-P. Launay, Electron transfer in molecular binuclear complexes and relation with electron transport through nanojunctions. Coord. Chem. Rev. 2013, 257, 1544-1554.

[2] R. Sakamoto, S. Katagiri, H. Maeda, H. Nishihara, Bis(terpyridine) metal complex wires: Excellent long-range electron transfer ability and controllable intrawire redox conduction on silicon electrode. Coord. Chem. Rev. 2013, 257, 1493-1506.

[3] Y. Yuan, J. F. Yan, D. Q. Lin, B. W. Mao, Y. F. Yuan, FerroceneAlkynyl Conjugated Molecular Wires: Synthesis, Characterization, and Conductance Properties. Chem. Eur. J. 2018, 24, 3545-3555.

[4] L. Yu, J. F. Yang, B. Y. Guan, Y. Lu, X. W. D. Lou, Hierarchical Hollow Nanoprisms Based on Ultrathin Ni-Fe Layered Double Hydroxide Nanosheets with Enhanced Electrocatalytic Activity towards Oxygen Evolution. Angew. Chem. Int. Ed. 2018, 57, 172 176.

[5] E. J. Piechota, L. Troian-Gautier, R. N. Sampaio, M. K. Brennaman K. Hu, C. P. Berlinguette, G. J. Meyer, Optical Intramolecular Electron Transfer in Opposite Directions through the Same Bridge That Follows Different Pathways. J. Am. Chem. Soc. 2018, 140, 7176-7186.

[6] C. Simão, M. Mas-Torrent, N. Crivillers, V. Lloveras, J. M. Artés, P. Gorostiza, J. Veciana, C. Rovira, A robust molecular platform for non-volatile memory devices with optical and magnetic responses. Nat. Chem. 2011, 3, 359.

[7] D.-L. Ma, V. P.-Y. Ma, D. S.-H. Chan, K.-H. Leung, H.-Z. He, C.-H. Leung, Recent advances in luminescent heavy metal complexes for sensing. Coord. Chem. Rev. 2012, 256, 3087-3113.

[8] B.-B. Cui, Y.-W. Zhong, J. Yao, Three-State Near-Infrared Electrochromism at the Molecular Scale. J. Am. Chem. Soc. 2015 , 137, 4058-4061.

[9] C. Creutz, H. Taube, Direct approach to measuring the FranckCondon barrier to electron transfer between metal ions. J. Am. Chem. Soc. 1969, 91, 3988-3989.

[10] J. Hankache, O. S. Wenger, Organic Mixed Valence. Chem. Rev 2011, 111, 5138-5178.

[11] G. E. Pieslinger, P. Albores, L. D. Slep, L. M. Baraldo, Class III delocalization in a cyanide-bridged trimetallic mixed-valence complex. Angew. Chem. Int. Ed. 2014, 53, 1293-1296.

[12] X. Ma, C. S. Lin, X. Q. Zhu, S. M. Hu, T. L. Sheng, X. T. Wu, An Unusually Delocalized Mixed-Valence State of a CyanidometalBridged Compound Induced by Thermal Electron Transfer. Angew. Chem. Int. Ed. 2017, 56, 1605-1609.

[13] M. M. Hansmann, M. Melaimi, G. Bertrand, Organic Mixed Valence Compounds Derived from Cyclic (Alkyl)(amino)carbenes. J. Am. Chem. Soc. 2018, 140, 2206-2213.

[14] Y. Y. Yang, X. Q. Zhu, S. M. Hu, S. D. Su, L. T. Zhang, Y. H. Wen, X. T. Wu, T. L. Sheng, Different Degrees of Electron Delocalization in Mixed Valence Ru-Ru-Ru Compounds by Cyanido-/IsocyanidoBridge Isomerism. Angew. Chem. Int. Ed. 2018, 57, 14046-14050. 
J. Maurer, R. F. Winter, B. Sarkar, J. Fiedler, S. Záliš, Bridgedominated oxidation of a diruthenium 1,3-divinylphenylene complex. Chem. Commun. 2004, 1900-1901.

J. Maurer, B. Sarkar, B. Schwederski, W. Kaim, R. F. Winter and S. Záliš, Divinylphenylene-bridged diruthenium complexes bearing $\mathrm{Ru}(\mathrm{CO}) \mathrm{Cl}\left(\mathrm{PiPr}_{3}\right)_{2}$ entities. Organometallics 2006, 25, 3701-3712.

P. Mücke, M. Linseis, S. Záliš and R. F. Winter, Vinyl-ruthenium entities as markers for intramolecular electron transfer processes. Inorg. Chim. Acta 2011, 374, 36-50.

J. Zhang, M.-X. Zhang, C.-F. Sun, M. Xu, F. Hartl, J. Yin, G.-A. Yu, L. Rao, S. H. Liu, Diruthenium Complexes with Bridging Diethynyl Polyaromatic Ligands: Synthesis, Spectroelectrochemistry, and Theoretical Calculations. Organometallics 2015, 34, 3967-3978. Y.-P. Ou, J. Zhang, F. Zhang, D. Kuang, F. Hartl, L. Rao, S. H. Liu, Notable differences between oxidized diruthenium complexes bridged by four isomeric diethynyl benzodithiophene ligands. Dalton Trans. 2016, 45, 6503-6516.

Y.-P. Ou, J. Zhang, M.-X. Zhang, F. Zhang, D. Kuang, F. Hartl, S. H. Liu, Bonding and Electronic Properties of Linear Diethynyl Oligothienoacene-Bridged Diruthenium Complexes and Their Oxidized Forms. Inorg. Chem. 2017, 56, 11074-11086.

C. Hassenrück, R. F. Winter, Manipulation and Assessment of Charge and Spin Delocalization in Mixed-Valent TriarylamineVinylruthenium Conjugates. Inorg. Chem. 2017, 56, 13517-13529. C.-J. Yao, Y.-W. Zhong, J. Yao, Charge Delocalization in a Cyclometalated Bisruthenium Complex Bridged by a Noninnocent 1,2,4,5-Tetra(2-pyridyl)benzene Ligand. J. Am. Chem. Soc. 2011, 133, 15697-15706.

S. H. Wadman, M. Lutz, F. Hartl, R. W. A. Havenith, G. P. M. van Klink and G. van Koten, Consequences of $N, C, N^{\prime}-$ and $C, N, N^{\prime}$ Coordination Modes on Electronic and Photophysical Properties of . Inorg. Chem 2009, 48, 1887-1900.

S. H. Wadman, R. W. A. Havenith, F. Hartl, A. L. Spek, G. P. M van Klink, and G. van Koten, Redox Chemistry and Electronic Properties of 2,3,5,6-Tetrakis(2-pyridyl)pyrazine-Bridged Diruthenium. Inorg. Chem. 2009, 48, 5685-5696.

5] L.-Z. Sui, W.-W. Yang, C.-J. Yao, H.-Y. Xie and Y. W. Zhong, Charge delocalization of 1,4-benzenedicyclometalated ruthenium: a comparison between tris-bidentate and bis-tridentate complexes. Inorg. Chem. 2012, 51,1590-1598.

J.-Y. Shao, W.-W. Yang, J. Yao and Y.-W. Zhong, Biscyclometalated ruthenium complexes bridged by 3,3 ',5, $5^{\prime}$ tetrakis( $\mathrm{N}$-methylbenzimidazol-2-yl)biphenyl: synthesis and spectroscopic and electronic coupling studies. Inorg. Chem. 2015, 51, 4343-4351.

L. Wang, W.-W. Yang, R.-H. Zheng, Q. Shi, Y.-W. Zhong and J. Yao, Electronic coupling between two cyclometalated ruthenium centers bridged by 1,3,6,8-tetrakis(1-butyl-1H-1,2,3-triazol-4yl)pyrene. Inorg. Chem. 2011, 50, 7074-7079.

J.-Y. Shao, Z.-L. Gong and Y.-W. Zhong, Bridged cyclometalated diruthenium complexes for fundamental electron transfer studies and multi-stage redox switching. Dalton Trans. 2018, 47, 23-29. W.-W. Yang, J.-Y. Shao and Y.-W. Zhong, Cyclometalated diruthenium complexes bridged by 3,3',5,5'-tetra(pyrid-2yl)biphenyl: tuning of electronic properties and intervalence charge transfer by terminal ligand effects. Eur. J. Inorg. Chem. 2015, 19, 3195-3204.
[30] Y.-W. Zhong, Z.-L. Gong, J.-Y. Shao and J. Yao, Electronic coupling in cyclometalated ruthenium complexes. Coord. Chem. Rev. 2016, 312, 22-40.

[31] J. F. Hull, D. Balcells, J. D. Blakemore, C. D. Incarvito, O. Eisenstein, G. W. Brudvig, R. H. Crabtree, Highly Active and Robust $\mathrm{Cp}^{*}$ Iridium Complexes for Catalytic Water Oxidation. J. Am. Chem. Soc. 2009, 131, 8730-8731.

[32] C. Wang, H.-Y. T. Chen, J. Bacsa, C. R. A. Catlow, J. Xiao, Synthesis and X-ray structures of cyclometalated iridium complexes including the hydrides. Dalton Trans. 2013, 42, 935-940. M. Talavera, A. Peña-Gallego, J. L. Alonso-Gómez, S. Bolaño, Metallaaromatic biaryl atropisomers. Chem. Commun. 2018, 54, 10974-10976.

[34] Y.-F. Han, H. Li, L.-H. Weng, G.-X. Jin, Efficient formation of organoiridium macrocycles via $\mathrm{C}-\mathrm{H}$ activation directed selfassembly. Chem. Commun. 2010, 46, 3556-3558.

[35] H. Li, Y.-F. Han, G.-X. Jin, Bis-imine-cyclometalated macrocycles: synthesis, characterization and observation of solution behaviour. Dalton Trans. 2011, 40, 4982-4993.

[36] C. White, A. Yates, P. M. Maitlis, D. M. Heinekey, ( $\eta^{5}$ Pentamethylcyclopentadienyl)Rhodium and -Iridium Compounds. Inorg. Synth. 1992, 29, 228-234.

[37] M. A. Esteruelas, A. B. Masamunt, M. Oliván, E. Oñate, M. Valencia, Aromatic Diosmatricyclic Nitrogen-Containing Compounds. J. Am. Chem. Soc. 2008, 130, 11612-11613.

[38] J. M. Fernández-Hernández, C.-H. Yang, J. I. Beltrán, V. Lemaur, F. Polo, R. Fröhlich, J. Cornil, L. De Cola, Control of the Mutual Arrangement of Cyclometalated Ligands in Cationic Iridium(III) Complexes. Synthesis, Spectroscopy, and Electroluminescence of the Different Isomers. J. Am. Chem. Soc. 2011, 133, 10543-10558.

[39] A. B. Tamayo, B. D. Alleyne, P. I. Djurovich, S. Lamansky, I. Tsyba, N. N. Ho, R. Bau, M. E. Thompson, Synthesis and Characterization of Facial and Meridional Tris-cyclometalated Iridium(III) Complexes. J. Am. Chem. Soc. 2003, 125, 7377-7387.

[40] Y. Hu, Y. Dong, X. Sun, G. Zuo, J. Yin, S. H. Liu, Benzoiridacyclopentadiene complexes: Mechanochromism and the effects of counter anions and halogen ligands. Dyes Pigments 2018, 156, 260-266.

[41] S. Komiya, Synthesis of Organometallic Compounds (Wiley, Chichester, 1997).

[42] Sheldrick, G. M. SHELXS-97, a Program for Crystal Structure Solution; University of Göttingen: Göttingen, Germany, 1997.

[43] O. V. Dolomanov, L. J. Bourhis, R. J. Gildea, J. A. K. Howard, H. Puschmann, OLEX2: a complete structure solution, refinement and analysis program. J. Appl. Crystallogr. 2009, 42, 339-341.

[44] M. Krejčík, M. Daněk, F. Hartl, Simple construction of an infrared optically transparent thin-layer electrochemical cell: Applications to the redox reactions of ferrocene, $\mathrm{Mn}_{2}(\mathrm{CO})_{10}$ and $\mathrm{Mn}(\mathrm{CO})_{3}(3,5-\mathrm{di}-\mathrm{t}$ butyl-catecholate) ${ }^{-}$. J. Electroanal. Chem. Interfacial Electrochem. 1991, 317, 179-187.

[45] M. J. Frisch, G. W. Trucks, H. B. Schlegel, G. E. Scuseria, M. A. Robb, J. R. Cheeseman, G. Scalmani, V. Barone, B. Mennucci, G. A. Petersson, H. Nakatsuji, M. Caricato, X. Li, H. P. Hratchian, A. F. Izmaylov, J. Bloino, G. Zheng, J. L. Sonnenberg, M. Hada, M. Ehara, K. Toyota, R. Fukuda, J. Hasegawa, M. Ishida, T. Nakajima, Y. Honda, O. Kitao, H. Nakai, T. Vreven, J. A. Montgomery Jr., J. E. Peralta, F. Ogliaro, M. Bearpark, J. J. Heyd, E. Brothers, K. N. 
Kudin, V. N. Staroverov, R. Kobayashi, J. Normand, K. Raghavachari, A. Rendell, J. C. Burant, S. S. lyengar, J. Tomasi, M. Cossi, N. Rega, J. M. Millam, M. Klene, J. E. Knox, J. B. Cross, V. Bakken, C. Adamo, J. Jaramillo, R. Gomperts, R. E. Stratmann, O. Yazyev, A. J. Austin, R. Cammi, C. Pomelli, J. W. Ochterski, R. L. Martin, K. Morokuma, V. G. Zakrzewski, G. A. Voth, P. Salvador, J. J. Dannenberg, S. Dapprich, A. D. Daniels, Ö. Farkas, J. B.
Foresman, J. V. Ortiz, J. Cioslowski and D. J. Fox, Gaussian 09, Revision D.01, Gaussian, Inc., Wallingford CT, 2009.

[46] M. Cossi, N. Rega, G. Scalmani, V. Barone, Energies, structures, and electronic properties of molecules in solution with the C-PCM solvation model. J. Comput. Chem. 2003, 24, 669-681. 
Entry for the Table of Contents (Please choose one layout)

Layout 1:

\section{FULL PAPER}

Two isomer pairs of cyclometalated diiridium complexes, with $\operatorname{IrCp}^{*} \mathrm{Cl}$ termini bridged by 1,4- and 1,3$\operatorname{bis}(p$-tolylimino-ethyl)benzene, or 1,4- and 1,3-bis(2-pyridyl)benzene, were prepared and fully characterized. Their different bonding and electronic properties in the neutral and monocationic states were studied by experimental spectro-electrochemical methods and DFT/TD-DFT calculations.

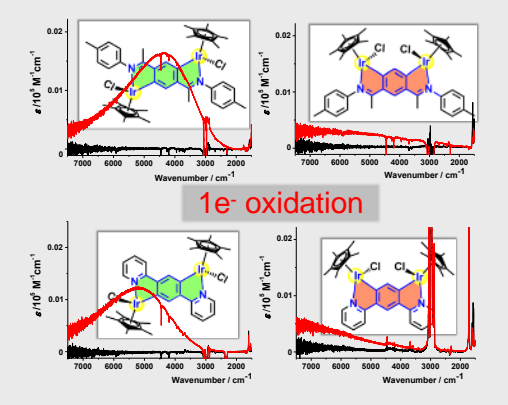

Yu Xuan Hu, Jing Zhang, Fangfang Zhang, Xiaoyan Wang, Jun Yin, František Hartl* and Sheng Hua Liu*

Electronic properties of oxidized cyclometalated diiridium complexes: Spin delocalization controlled by the mutual position of the iridium centres 